\title{
TROCA ENTRE UNIVERSIDADE E ESCOLA NA FORMAÇÃO DOCENTE: UMA EXPERIÊNCIA DE FORMAÇÃO INICIAL E CONTINUADA
}

\section{Interaction between university and school in teachers education: an experience in pre-service and in-service education}

\author{
Nora Ney Santos Barcelos ${ }^{1}$ \\ Alberto Villani ${ }^{2}$
}

\begin{abstract}
Resumo: Apresentamos neste trabalho uma experiência de formação continuada com professores do ensino fundamental de uma escola pública estadual, que envolveu também licenciandos de um curso de Ciências Biológicas. 0 ponto fundamental foi o início de colaboração entre Universidade e Escola que a pesquisadora, responsável tanto pela formação inicial quanto continuada, conseguiu realizar. Isso permitiu o desenvolvimento de uma mudança curricular por parte dos professores da escola, assim como uma reflexão mais aprofundada dos estagiários sobre a realidade escolar e a prática docente. A análise e interpretação será conduzida a partir de um referencial psicanalítico, privilegiando as modificações no saber e na satisfação dos sujeitos envolvidos.
\end{abstract}

Palavras-chave: Formação continuada. Formação inicial. Assessoria pedagógica. Psicanálise e educação.

Abstract: In this work we show an example of in-service teachers' education, in a public elementary school, which also involved also future teachers in Biology. The most important point was the collaboration between University and School, enabled by the researcher who was responsible both for preservice and in-service teachers' education. This allowed the development of curricular change by the schoolteachers and a deepening of the students' reflection about the reality of school and teaching practice. The analysis and interpretation is based on a psychoanalytical reference and focuses on the change in the understanding and satisfaction about subjects.

Keywords: In-service and pre-service education. Pedagogical assesment. Psychoanalysis and education.

${ }^{1}$ D ocente, Universidade Federal de Uberlândia, Universidade de São Paulo, Faculdade de Educação.

$<$ noraney@uai.com.br>

${ }^{2}$ D ocente, Universidade de São Paulo, Instituto de Física. Com auxílio parcial do CNPq. <avillani@ if.usp.br> 


\section{Introdução}

Os programas de formação continuada freqüentemente consistem de uma série de atividades pedagógicas prontas, na esperança de que os professores sejam capazes de reproduzi-las em sala de aula. No entanto, essas propostas parecem desconsiderar os contextos específicos do ambiente macro e micro escolar em que atuam os professores participantes e, por isso, não chegam a ser incorporadas como um saber ativo. Recentemente, várias iniciativas estão modificando esta tendência, conseguindo tornar alguns professores multiplicadores de inovações curriculares como, por exemplo, na Escola Plural, em Belo Horizonte (PMBH, 1994). No entanto, na maioria das experiências deste tipo, os projetos dificilmente conseguiram manter uma continuidade institucional para além da experiência específica (GARRID 0 et al., 2000; COLLARES e MOISES, 1995; PACCA e VILLANI, 1997). Em geral, podemos afirmar que os professores envolvidos em projetos de formação continuada continuam tendo dificuldades para transferir a suposta atualização no coletivo da escola (VILLANI et al., 2002).

Também no caso da formação inicial têm sido realizadas várias experiências bem sucedidas, nas quais a escola tem oferecido uma colaboração significativa monitorando efetivamente a atuação dos licenciandos (CO MPIANI, 2001) e reconhecendo e prestigiando a contribuição destes na formação dos alunos (BARO LLI et al., 2001). Entretanto, em geral 0 problema parece permanecer. D e um lado, a pouca articulação entre as várias atividades que constituem o currículo de formação dos licenciandos na universidade parece minar a possibilidade de visibilidade das propostas teóricas apresentadas. De outro lado, a falta de projetos que fortaleçam os vínculos entre a Educação Superior nas instituições formadoras de professores e as instituições de Educação Básica, para que haja trocas entre a universidade e a escola, parece tornar a formação inicial muito teórica e pouco realista. D e fato, os estágios dos futuros professores e a participação dos formadores de professores na escola ainda não fazem parte do projeto político pedagógico da escola e nem da universidade. Os supervisores de estágio dificilmente conseguem ir além de refletir juntos com os estagiários a realidade e as ações por eles realizadas nas escolas, sob a luz dos referenciais teóricos. E, neste ambiente, raramente são provocadas mudanças nas crenças, valores e atitudes dos futuros professores em relação ao ensino perante as novas demandas científicas, políticas e sócio-culturais. Neste contexto, os estagiários mais críticos e comprometidos acabam se sentindo alvo de contradições e promessas não concretizadas, pessoas estranhas à escola, para não dizer, em algumas situações, indesejadas.

As novas diretrizes do Ministério da Educação sobre Formação de Professores para a Educação Básica (MEC, 2001) convocam os formadores de professores a refletirem sobre dois aspectos: tornar a formação inicial de professores um efetivo projeto coletivo, capaz de envolver a instituição formadora e o conjunto de formadores, e estabelecer uma parceria com a escola, na qual estagiários, professores e supervisores de estágio, juntos, possam aprender a trabalhar profissionalmente no cotidiano escolar. Certamente, pôr em prática estas diretrizes não será simples, sendo bem vindas as tentativas realizadas a esse respeito.

Neste trabalho será analisada uma longa experiência de formação continuada que envolveu, também, licenciandos de Ciências e de Biologia e contribuiu de maneira especial para sua formação inicial. 0 ponto fundamental foi a experiência inicial de acoplamento entre universidade e escola que a pesquisadora, responsável pela formação inicial e a continuada, 
conseguiu realizar. Isso permitiu o desenvolvimento de uma mudança curricular por parte dos professores da escola, assim como uma reflexão mais aprofundada dos estagiários sobre a realidade escolar e a prática docente, modificando suas crenças, seus sentimentos e suas posturas pessoais em relação à mesma. Permitiu, também, o início de colaboração efetiva da universidade com a escola.

Após apresentar a metodologia de pesquisa e os referenciais de análise, o trabalho será desenvolvido em três partes: a) descrição e interpretação sobre a inserção da pesquisadora na escola e suas intervenções como assessora pedagógica voluntária; b) explicitação dos desdobramentos da pesquisa envolvendo a formação inicial e continuada, procurando salientar os mecanismos que tornaram a experiência significativa; c) reflexão sobre os resultados na busca de ampliar as perspectivas de colaboração escola-universidade, propondo o esboço de uma formação docente na escolla.

\section{A metodologia de pesquisa e os referenciais teóricos}

Inicialmente, a pesquisa foi planejada com a finalidade de investigar, numa escola estadual de Ensino Fundamental, o saber docente dos professores sobre Educação e O rientação Sexual e, simultaneamente, promover uma mudança em sua prática didática que explorasse esse saber. A pesquisa, de tipo qualitativo - uma pesquisa-ação colaborativa (BARBIER, 1997 ) começou em março de 1999 e terminou em final de 2001. Progressivamente modificou seu rumo, envolvendo aos poucos os professores e colaboradores da escola e, também, vários licenciandos da universidade que participaram da experiência. Houve modificação das atividades, tanto na escola quanto na universidade, para englobar o ensino pelo método de projeto na experiência.

Nossos dados de pesquisas consistem de anotações da pesquisadora, realizadas ao longo da pesquisa, de registros feitos pelos licenciandos em seus portfólios e de gravações em vídeo de alguns encontros entre eles e a pesquisadora. Houve, também, entrevistas, com quatro professoras da escola que aceitaram contar suas trajetórias profissionais e refletir sobre as mesmas. Essas narrações, após transcritas e semi-analisadas pela pesquisadora, foram discutidas, com a permissão das entrevistadas, com os demais professores da escola e, posteriormente, com os licenciandos na universidade.

Todos os dados foram analisados pelos autores deste trabalho em duas etapas: num primeiro momento, procurou-se estabelecer um relato consistente dos eventos mais significativos que ocorreram ao longo dos três anos de experiência. Num segundo momento, esse relato foi interpretado a partir de um referencial teórico fundamentado, principalmente, numa abordagem de origem psicanalítica. A interpretação, além de articular de forma mais coerente o relato dos eventos, introduziu questões que remeteram novamente aos dados de pesquisa e à sua complementação via lembranças específicas da pesquisadora.

Em nosso referencial, existe uma diferença entre a apropriação de uma informação e de um conhecimento, e a elaboração de um saber pessoal. Assim, considera-se que o resultado final objetivado pela formação do professor, seja inicial ou continuada, é a promoção de saberes docentes que constituam o guia da ação docente e das correspondentes escolhas didáticas. Os saberes docentes têm ramificações conscientes e inconscientes, pois são tecidos com investi- 
mento próprio e atingem a satisfação e o desejo do professor e sua relação com o conhecimento (MRECH, 1999; FREITAS et al., 2000). Conseqüentemente, eles não podem ser atingidos totalmente pela instrução, porém têm nela o ponto de partida e a condição de desenvolvimento. Em nosso referencial, favorecer a elaboração de um novo saber por parte do docente aprendiz implica necessariamente enfrentar uma tensão: de um lado, o formador deve cuidar para que a mudança pretendida seja mais próxima possível do conhecimento pedagógicocientífico estabelecido; de outro, deve ser deixado espaço para que o saber pessoal do aprendiz seja colocado em jogo e moldado segundo seus próprios ritmos e critérios. Em nossa interpretação privilegiamos dois elementos como reguladores do processo de formação docente: 0 outro $^{3}$ (a referência inconsciente) e o gozo $^{4}$ (a satisfação inconsciente, FINK, 1998). Neste processo, por um lado, se o formador for colocado na posição de outro pelo formando, via transferência ${ }^{5}$ pedagógica, terá a possibilidade efetiva de influenciá-lo e de atingir seu saber pessoal; por outro lado, o formando poderá sustentar-se no processo de maneira estável, somente deslocando para o novo saber parte de sua satisfação inconsciente anteriormente alocada em outros saberes e/ ou circuitos inerciais.

\section{A inserção da pesquisadora na escola}

A pesquisadora em questão, cuja competência específica dizia respeito à formação inicial de professores e à orientação sexual, tinha elaborado um projeto de pesquisa que permitia obter informações sobre a disponibilidade dos professores de assumirem um ensino compatível com a nova orientação curricular e sobre as dificuldades para colocarem em prática as mudanças. Para que sua intervenção pudesse ser incorporada ao cotidiano da escola, apresentou e comentou com a diretora e, posteriormente, com os professores, um projeto de trabalho pelo qual ela assumiria uma assessoria pedagógica geral, a ser realizada voluntariamente.

\section{As observações iniciais}

O relato da pesquisadora (BARCELOS, 2001) informa várias características da comunidade escolar.

Havia uma manifestação contínua de queixas-lamento (FERNANDEZ, 1994) dos professores e dos alunos, sugerindo tanto uma fuga das dificuldades da prática docente quanto falta de investimento na aprendizagem:

\footnotetext{
${ }^{3}$ Outro (grande $\mathrm{O}$ utro) indica a referência implícita, introduzida quando a criança entra na linguagem. Inicialmente seus representantes são os pais, posteriormente qualquer instância social que a capture e a quem ela preste conta.

${ }^{4} \mathrm{O}$ gozo corresponde à hipótese teórica da presença de uma satisfação inconsciente

todas as vezes que o indivíduo se amarra em situações repetitivas. D o ponto de vista psíquico, o gozo geralmente envolve algum componente prazeroso, porém implica também uma tensão crescente.

${ }^{5}$ A transferência é o processo pelo qual o paciente atribui inconscientemente poderes oriundos da relação familiar para 0 analista, reconhecendo nele a possibilidade de solução de seus próprios problemas e sofrimentos. A transferência pedagógica é atribuição desses poderes para o professor no ambito da relação escolar.
} 
"É muito difícil dar aula para muitos alunos por classe".

"Os alunos desrespeitam os professores e não têm interesse pelas aulas".

"Os alunos, agora com a reforma, não vão estudar mesmo".

"N essa escola nada funciona e todas as iniciativas fracassam".

"A lguns professores são chatos, gritam e não se interessam pelos alunos".

"0 professor fala o tempo todo, escreve no quadro e somente manda 0 aluno copiar".

No entanto, havia, também, propostas concretas:

"E stou querendo trabalhar om os alunos da 7ª série um livro paradidátioo que aborda a vida de uma adolescente portadora de $\mathrm{H} \mathrm{IV} \mathrm{".}$

"Os alunos não sabem trabalhar em grupo. Como eu posso fazer?".

Também havia indícios de movimento por parte de professores: iniciativas como 'Anjo da Esperança $^{\boldsymbol{G}^{\prime}}$ ou 'Retratinho da Turma $^{\mathbf{7}^{\prime}}$ revelavam esperança e desejo em mudar, de sair das queixas-lamento para melhorar o clima geral. Entretanto, a adesão parcial de professores e alunos às iniciativas, o boicote de alguns professores e a resistência de alunos em dialogar com alguns de seus professores refletiam uma tensão interna na escola, que consumia boa parte da energia de todos. Essa divisão recortava o próprio querer da maioria dos professores, que oscilava entre 0 desejo de mudar, para criar um novo ambiente de aprendizagem, e 0 apego ao 'saber tradicional', baseado na disciplina, ordem e no silêncio, no qual encontravam uma forma de satisfação. Parece evidente que a ruptura do impasse somente poderia acontecer mediante uma ex periência satisfatória que aumentasse a necessidade de mudança e diminuísse 0 apego aos valores tradicionais. Para tanto, necessitava de um outro, que orientasse os desejos e minimizasse as perdas, mas, naquele momento, ninguém estava sendo colocado nessa posição.

Além dessas dificuldades específicas, a comunidade escolar estava sendo inserida no circuito de mudanças curriculares, as quais exigiam que a aprendizagem social e cultural de valores fosse incorporada ao desempenho e rendimento dos alunos. Simultaneamente, a Superintendência Regional de Ensino (SRE) pressionava para que as reformas curriculares, que visavam à organização do ensino em ciclos, com progressão continuada e novo tipo de avaliação, fossem realizadas rapidamente, sobretudo introduzindo mudanças didáticas necessárias. Por outro lado, a própria administração da escola transferia somente em parte essa pressão para o corpo docente, talvez acreditando que o tempo resolveria o problema.

Q uanto à presença da pesquisadora, o primeiro desafio foi ser reconhecida como assessora pedagógica sem ocupar um cargo institucionalmente reconhecido. 0 caminho inicial foi participar sistematicamente dos eventos comuns, após pedir permissão para a diretora da

\footnotetext{
${ }^{6}$ Este projeto foi proposto por um professor, que, visando enfrentar as dificuldades dos alunos em relação à escola, família, trabalho, sociedade e a situação financeira, sugeriu a criação de um professor/ a 'conselheiro ' para cada turma.

${ }^{7}$ Este projeto foi proposto pela pedagoga educacional, que se dispôs a conversar com alunos e professores, individualmente, em grupo ou em classe, para levantar os aspectos positivos e negativos da sala de aula e da escola e iniciar a abordagem de temas de interesse dos alunos.
} 
escola. Por meio de discussões informais, individuais ou em pequenos grupos, introduzia considerações teóricas e práticas sobre a relação professor-aluno, a ambigüidade da linguagem, 0 trabalho em grupos, o método de projeto e a avaliação da aprendizagem. Assim, conseguiu estabelecer uma colaboração mais freqüente e concreta com os professores: permanecia na escola uma ou duas manhãs por semana, na hora do recreio e nos intervalos de aula, ouvindo os professores em suas queixas e experiências de sala de aula, auxiliando-os a enfrentarem, com mais otimismo, as turbulências diárias. Algumas vezes participava ativamente, assumindo determinadas tarefas em sala de aula que os professores tendiam a recusar, como falar sobre "A dolesônncia, etica e cidadania" ou apresentar novas orientações sobre avaliação.

A escolha da entrada na escola como assessora pedagógica voluntária, sem uma tarefa específica, teve várias conseqüências. Implicou um tempo longo (praticamente todo o primeiro semestre de 1999) em contatos eventuais e casuais com os professores e alunos, pois a diretora permitiu sua presença, mas não favoreceu sua participação ativa nas poucas reuniões pedagógicas que aconteciam na escola. Os professores, inicialmente, sentiam-se inseguros em relação a ela e, por isso, não revelavam suas práticas e nem solicitavam sua ajuda. Por outro lado, a pesquisadora vivia a angústia causada pela própria inércia, pois assistia, sem poder intervir de forma mais efetiva, a situações que mostravam as dificuldades do corpo docente e pedagógico da escola em relação às propostas que exigiam dos professores mais compromisso com a formação integral dos alunos e, conseqüentemente, mudanças didáticas na própria prática docente. D iante de tais circunstâncias, modificou sua visão em relação às dificuldades mais urgentes a serem enfrentadas naquele momento pela escola, deslocando o foco de sua atuação da promoção de uma formação docente sobre sexualidade para o incentivo de uma prática comunitária e dos correspondentes saberes docentes. Conseqüentemente, mudou também o objeto de sua pesquisa. Provavelmente, sua atuação inicial pouco perturbadora e sua atenção e adaptação ao contexto da escola permitiram que os professores se acostumassem progressivamente com sua presença, reconhecendo-a não como uma pesquisadora externa, somente preocupada com seus dados, mas, sim, como uma possível colaboradora pedagógica.

Simultaneamente à atividade de pesquisadora, a assessora exercia sua função de professora na universidade, como formadora de futuros professores de Ciências e de Biologia. Uma das atividades iniciais da disciplina por ela ministrada era chamada: $\mathrm{C}$ onheça uma E scola ${ }^{8}$. Naquele ano, um dos grupos de licenciandos visitou a escola na qual ela atuava como pesquisadora. Assim, tanto os licenciandos quanto a formadora, pela maior participação na vida da escola, tiveram acesso a informações de primeira mão da própria escola e também das iniciativas da SRE e da Secretaria Estadual de E ducação (SEE-MG). A reflexão dos estudantes foi ampliada, aproximando todos os licenciandos da realidade escolar e envolvendo-os na discussão dos problemas da escola. Também foi planejado que a assessora procuraria ter uma participação mais direta na vida da escola e, se possível, envolveria os licenciandos em projetos,

\footnotetext{
${ }^{8}$ Cada grupo de licenciandos-estagiários visitava uma escola pública ou particular da cidade, observando e registrando, em portfólios pessoais, os episódios e suas interpretações sobre o comportamento dos alunos, dos professores e dos profissionais de apoio no cotidiano da escola diante das políticas e reformas educacionais. Em seguida os conteúdos destes portfólios eram discutidos em classe com a professora
} 
principalmente de formação afetivo-sexual, o que atenderia à demanda de muitos professores e poderia solucionar parte dos impasses na relação entre professores e alunos.

\section{As primeiras intervenções}

A primeira ocasião para realizar este avanço foi durante um encontro da assessora com os alunos da escola, programado a partir da solicitação de alguns professores e da pedagoga educacional. 0 relato da assessora sobre 0 encontro foi sucessivamente explorado na discussão com os licenciandos para salientar a disponibilidade e 0 interesse dos alunos quando as atividades tornaram-se significativas para eles. Outra novidade da experiência foi convidar, para auxiliar no monitoramento das atividades, dois ex-alunos para coordenarem duas dinâmicas. Na primeira, o tema foi: "A vulnerabilidade do corpo diante do víco" e a estagiária relatou que se sentiu ajudada, principalmente, no momento de elaborar sínteses satisfatórias a partir de seus referenciais teóricos e das questões e opiniões dos alunos. Na segunda dinâmica, "Sex ualidade e E cologia", a habilidade do estagiário na condução foi grande, surpreendendo a própria assessora, que na síntese final elogiou a "transposição didática", para a sala de aula, de diferentes conteúdos trabalhados na universidade. $O$ resultado da experiência foi considerado amplamente positivo pelos alunos, licenciandos e pela assessora, inclusive para firmar a importância de sua presença na escola, a partir dos comentários bastante favoráveis dos professores e alunos. Estava iniciado seu deslocamento para a posição de outro na escola.

Uma segunda ocasião de intervenção colaborativa da assessora ocorreu com a participação na excursão ao Parque Ecológico, atividade sugerida pelos professores de Ciências para repor aulas não ministradas por ocasião de um protesto contra medidas do governo estadual. A assessora conseguiu adesão dos professores de todas as disciplinas para um planejamento interdisciplinar, que seria desenvolvido por um roteiro integrado durante a excursão e, sucessivamente, mediante avaliação comum na sala de aula. A elaboração do roteiro foi o ponto mais alto da atividade, pois houve contribuições interessantes de professores de todas as áreas disciplinares. Talvez pela primeira vez o corpo docente tenha operado numa perspectiva unitária e experimentado a correspondente satisfação de vislumbrar um efeito positivo.

No desenvolvimento da excursão apareceram dificuldades, pois alguns professores não acompanharam os alunos e outros não conseguiram atuar como guia-orientador. Uma das novidades dessa experiência foi a participação de quatro licenciandas, alunas da assessora na universidade, que realizavam, na escola, a atividade 'Conheça uma Escola'.

\footnotetext{
"Sentimos falta de uma reunião com todos os professores para discutirmos sobre a aula de campo e os resultados... L emos o relatório dos alunos que acompanhamos. No dia seguinte à ex cursão fomos assistir à aula de Ciências e ficamos surpresos, porque não se falou nada sobre a ex cursão ao parque e sobre as perguntas (do roteiro). D iante disso, fizemos entrevista com dois alunos. M esmo com a pouca convivência na escola consideramos que a experiência foi interessante para nós..."
}

Q uando este relato foi discutido em sala de aula na universidade provocou intensa participação, no esforço de focalizar os aspectos positivos e negativos da excursão ao parque. De fato, as estagiárias relataram que nas duas semanas seguintes parecia que o projeto não tivesse acontecido, pois professores e alunos só pensavam - e falavam - sobre provas bimestrais, apesar das tentativas de alunos, professores e da pedagoga para cumprir a parte final do 
projeto: elaborar textos dissertativos, jornalísticos ou descritivos sobre a excursão. No entanto, passadas as provas, os alunos sempre comentavam sobre a excursão, dizendo que haviam gostado muito. Os alunos que fizeram a avaliação por escrito desse evento confirmavam os comentários dos colegas.

\footnotetext{
"E u achei muito bom, ajudou bastante. Tinha questões de Matemática, Português... Foi muito interessante trabalhar com todas as disciplinas".

" 0 parque serviu como fonte de muitos conhecimentos, tinha uma placa na entrada que falava de sua história... Percebi que tinha condição para aprender G eometria, G eografia....".
} favorável.

Também os professores não deixaram de comentar o evento, quase sempre de modo
"Foi muito bom, tudo correu bem. M uita coragem levar tantos alunos num lugar como este".
"Pelo que ouvi, os alunos gostaram muito... eu não cansei nada.. O s tex tos estão sendo trabalhados lentamente, pois estamos em fase de prova".

Algumas reflexões podem ser feitas a partir desses depoimentos. A primeira é que alguns professores ficaram surpresos com a grande disponibilidade dos alunos para participar de eventos que se afastavam da rotina, tanto dentro da sala de aula quanto fora dela. Não somente havia aceitação das novas propostas didáticas, mas, também, diálogo e envolvimento criativo. Também começava a aparecer, nos comentários informais dos professores, a idéia de que as possibilidades de sucesso dos projetos aumentariam significativamente caso fossem realizadas ações coletivas, sendo que as mudanças esperadas dificilmente poderiam ser realizadas se cada um investisse, à revelia, na sala de aula, de acordo com suas crenças e possibilidades. Por outro lado, os professores consideravam que a diretoria funcionava mais permitindo 0 surgimento de iniciativas que orientando-as e sustentando-as.

Uma terceira reflexão, também importante, refere-se à disponibilidade de vários professores de aceitar - e até sugerir - a colaboração da pesquisadora. 0 depoimento de um professor: "0 sucesso de alguma oisa na esolla depende de quem a propõe", parece reforçar a importância de alguém externo para mediar a elaboração e o desenvolvimento do projeto político pedagógico da escola. Os professores começavam a perceber que na proposição de algo inovador era preciso considerar a oportunidade da situação, o interesse dos alunos e, também, a existência de alguém capaz de intermediar e facilitar o diálogo entre os vários membros da comunidade escolar. Vários professores estavam percebendo que as intervenções da assessora, às vezes, mudavam o rumo dos eventos e então começaram a se agrupar ao redor dela, aceitando sua liderança nessa tarefa. Começaram, também, a investir na busca de mudanças, reorientando seu saber anterior a respeito ou experimentando pela primeira vez a satisfação de uma ação em comum. Por outro lado, a diretoria desenvolvia uma mediação ambígüa: às vezes pressionando em favor de mudanças, as vezes dificultando sua organização.

Finalmente, importa destacar a participação dos estagiários que se integraram efetivamente à equipe escolar, cooperando ativamente com a assessora e com os professores para que as experiências tivessem êxito. Além de desenvolver competências docentes nos estagiários, isso permitiu também que eles percebesssem que os professores estavam assumindo, progres- 
sivamente, uma participação mais ativa na escola e, de alguma maneira, começavam a satisfazer implicitamente as demandas dos Parâmetros Curriculares Nacionais. Um novo saber profissional estava sendo desenvolvido neles: apontar, focalizar e interpretar os sinais de mudança da escola. Se desenvolvido, certamente este saber iria facilitar o futuro trabalho docente.

Uma nova ocasião de intervenção na escola por parte da pesquisadora ocorreu na preparação e realização da Feira Cientíío-C ultural, que habitualmente acontecia no segundo semestre. Com ajuda dos educadores, de uma ex-estagiária e dos alunos, a assessora conseguiu elaborar e desenvolver uma proposta inovadora, transformando uma atividade anteriormente padronizada, e não muito motivadora, num evento empolgante para a comunidade escolar. Seu relato a respeito é particularmente significativo para revelar a dinâmica dessa experiência pedagógica.

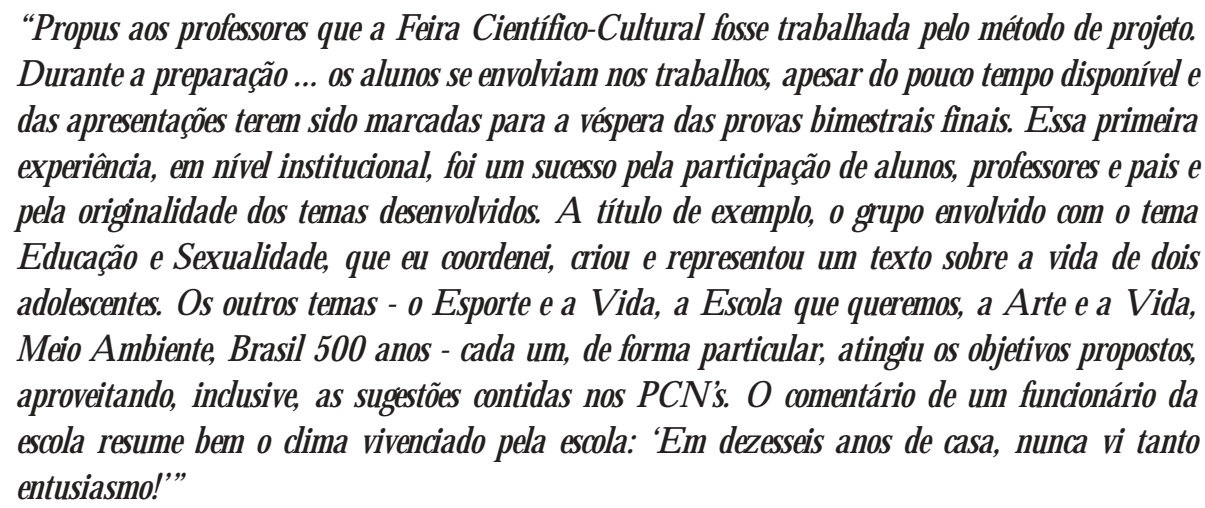

No caso específico do grupo coordenado pela assessora, os alunos se entusiasmaram pelo tema e foram procurar livros na biblioteca, começando a conversar mais e de forma natural sobre sexualidade com os colegas e pais. Para evitar mal-entendidos ou reações negativas dos professores e pais que participaram da apresentação, a assessora e a estagiária tiveram que fazer uma revisão de todos os textos preparados pelos alunos, antes da apresentação pública.

Naquele final de 1999 o movimento havia tomado conta da escola. A Feira, com seus temas do cotidiano e sua nova metodologia de preparação e apresentação dos trabalhos, contribuiu para fazer esquecer, em parte, os problemas curriculares. D e fato, a iniciativa conseguiu mobilizar toda a comunidade escolar - alunos, professores, pedagogos, pais, diretora e funcionários - em torno de um projeto da escola. A comunidade escolar pôde experimentar a satisfação de dar mais sentido social aos trabalhos, de tomar decisões em conjunto, de realizar ações coordenadas, de compartilhar com os pais o envolvimento de seus alunos. Já era possível acreditar que novos saberes docentes estavam sendo construídos ou, ao menos em parte, modificados, pois os professores tiveram que trabalhar, simultaneamente, com duas propostas pedagógicas: a preparação da Feira e as aulas normais da disciplina. $\mathrm{O}$ resultado positivo da experiência perturbou a crença na imutabilidade da prática escolar.

Além disso, uma nova relação era estabelecida com a pesquisadora. A convivência, agora quase que diária, fortaleceu a atitude de espera dos professores, sustentada pela fantasia de que ela iria dar conta de "resolver os problemas" que aparecessem. Ela era colocada na 
posição de outro. D esse modo, podia explorar a autoridade que os professores lhe atribuíam para trabalhar sistematicamente 0 confronto entre a demanda externa, os problemas reais e as potencialidades docentes, sugerindo implicitamente - ou mostrando explicitamente - que 0 guia para 0 avanço estava na permanente reflexão entre a prática realizada, as teorias que eventualmente eram introduzidas, as propostas da SEE-MG e as demandas dos alunos.

Assim, o primeiro ano de inserção e intervenção da pesquisadora numa dimensão colaborativa aconteceu nesta perspectiva: ocupando espaço vazio onde circulava a repetição de queixas lamento; explorando a relação de transferência pedagógica com professores e licenciandos; e contribuindo para a transformação das queixas em desafios, cuja solução estava na realização de ações coletivas.

Para a assessora, foi ficando claro que sua colaboração estava viabilizando mais aproximação entre os professores e superando alguns bloqueios que dificultavam a vivência do coletivo. Enfim, aos poucos, nos comentários informais já se consolidava a idéia de que as possibilidades de sucesso dos projetos aumentariam significativamente, caso houvesse realização de ações coletivas e descobertas conjuntas.

Simultaneamente, estava sendo realizada uma abertura da escola à universidade, com a participação de alguns licenciandos em atividades específicas da escola, com a finalidade de promover sua formação inicial. Isso permitiu circulação de dúvidas, queixas, descobertas e novas idéias, tanto no espaço escolar quanto no universitário, apontando a possibilidade de a assessoria pedagógica se tornar um dispositivo intermediário no estabelecimento de uma relação mais efetiva, permanente e continuada entre universidade e escola. Isso beneficiaria a formação inicial dos licenciandos e a formação continuada do corpo docente, pedagógico e administrativo da escola. Tratava-se de uma experiência nova, antes não experimentada pela pesquisadora em sua interação com 0 ensino superior e fundamental.

Em resumo, podemos interpretar que a pesquisadora encontrou a escola envolvida num dúplice circuito inercial: dos professores com os alunos, cada grupo acusando o outro de má vontade e aprofundando a falta de colaboração, e dos professores entre eles, desacreditados no sucesso de iniciativas de mudanças e colaborando para seu fracasso. Também encontrou um outro circuito inercial nos licenciandos, que focalizavam somente os aspectos negativos da vida escolar e, assim, aprofundavam o distanciamento dos professores e afastavam a vontade de intervir colaborando. Neste contexto, a mudança introduzida com um ano de assessoria da pesquisadora pode ser interpretada de duas maneiras diferentes, ambas corretas. De um lado, parece evidente que, apesar dos eventos interessantes e motivadores, a rotina da escola não sofreu modificações extraordinárias. Por outro lado, houve ruptura substancial dos circuitos inerciais, pois professores, alunos e licenciandos experimentaram situações novas de diálogo, colaboração e sucesso.

Assim, inconscientemente, os atores que operavam na escola eram colocados na possibilidade de escolher entre a satisfação mórbida das queixas-lamento e a satisfação da construção de novas iniciativas e novas relações. Naturalmente, para essa possibilidade se tornar concreta circunstâncias favoráveis deveriam sustentá-la, mas, de qualquer forma, constituiria a experiência de algo já conhecido. A contribuição mais importante da assessora foi ter promovido experiências que iam ao encontro da satisfação dominante e suspendiam simultaneamente os círculos viciosos instaurados na escola por professores, alunos e licenciandos. Com sua atuação ela conseguiu conquistar a posição de outro da escola e se confirmar como 
autoridade para os licenciandos, abrindo a possibilidade de maior influência nas atividades deles, na direção de uma experiência mais significativa. Estas poderiam ter-se tornado ainda mais promissoras se tivessem contado com a atuação simultânea da pesquisadora e de um número mais representativo e permanente de licenciandos, condição que, raramente, foi possível ao longo dos três anos de experiência, em razão da distribuição das disciplinas curriculares entre os docentes da universidade.

\section{Desenvolvendo projetos de formação continuada e inicial}

Uma vez instituido o lugar da assessora pedagógica na escola e a abertura mais explícita da escola para os licenciandos do curso de Ciências Biológicas, o processo de formação de professores e futuros professores se ampliou, apesar de sua estrutura artesanal constituir a base e o início, bastante precário, de uma via de mão dupla entre universidade e escola. D este trabalho privilegiaremos alguns projetos, desenvolvidos no segundo e terceiro ano de convivência da pesquisadora na escola, e que, por alguma razão, constituíram avanço efetivo nos processos de formação. No primeiro projeto contou-se com licenciandos estagiários bolsistas do $\mathrm{PET}^{9}$ ou voluntários ${ }^{10}$. Os outros dois, apesar das influências que exerceram na formação inicial dos licenciandos, focalizaram a formação continuada dos professores realizada no cotidiano da própria escola, investindo, prioritariamente, na metodologia de projetos para a inovação curricular. Todas estas atividades serviram de catalizadores de mudanças das crenças e atitudes da comunidade escolar e dos licenciandos-estagiários.

\section{O projeto Adolescência e Sexualidade Humana}

Este projeto foi desenvolvido a partir de uma diversidade de demandas: de alguns professores, de alunos, de licenciandos-estagiários e da pesquisadora. 0 projeto foi subdividido, abordando dois temas: "Relacooes interpessoais", desenvolvido pela assessora e uma psicóloga educacional (colega de trabalho da pesquisadora na universidade) para os professores e colaboradores da escola e pais dos alunos; e "A dolescência, sex ualidade humana e prevencãa", desenvolvido pelos estagiários com os alunos da escola.

$\mathrm{O}$ primeiro tema privilegiou as discussões entre os participantes, a partir de queixas dos professores aparecidas nas conversas casuais da sala de professores: as dificuldades no relacionamento com os alunos, a falta de motivação e de interesse de ambas as partes. A meta era atingir os participantes para que tornassem a comunicação mais acessível e os vínculos docentes mais afetivos.

Ao final do encontro uma professora comentou: "Eu acho que na 6a série precisa falar sobre sexualidade e higiene corporal. Eu acho que os professores de Ciências deveriam falar sobre isso. Quando a gente estava trabalhando com o teatro eles ficaram muito acanhados, tímidos, com vergonha e eu acho que isso deve ser trabalhado em Ciências".

\footnotetext{
${ }_{9}^{9}$ Programa Especial de Treinamento da CAPES.

${ }^{10}$ Ex-alunos da disciplina Educação-Saúde e Sexualidade.
} 
A pesquisadora perguntou: "Por que em Ciências? Você poderia ter proposto um desenho ou um texto sobre 0 assunto, higiene corporal e sexual, aproveitando o conteúdo do teatro (a vinda da família real para o Brasil) para gerar a discussão, que poderia, em seguida, ser aproveitada e explorada mais em Ciências".

Os licenciandos optaram por conduzir o projeto na forma de dois mini-cursos: " $\mathrm{G}$ ravidez" e "Sex ualidade na adolescência", os temas preferidos pelos alunos. Participaram cento e vinte alunos dos ciclos intermediário e avançado ( $5 \underline{a}$ a 8 a série) do Ensino Fundamental, que se envolveram na discussão dos temas, permitindo, inclusive, oportunidades para discussão de outros temas, como drogas, doenças, papéis e estereótipos sociais e preconceitos sexuais. A experiência foi considerada interessante e proveitosa, tanto pelos alunos quanto pelos licenciandos. Surpresas instigantes emergiram nos momentos destinados às avaliações formativas durante as atividades e quando os estagiários leram e discutiram as respostas dos alunos nos relatórios finais. Depoimentos como: "Gostei e aprendi muito; com os Estagiários tivemos mais liberdade para dar nossas opiniões e perguntar e ainda fizemos mais amigos", foram considerados significativos e gratificantes pelos licenciandos, apesar de reconhecerem as falhas da experiência, como apareceu no relatório final por eles elaborado:

\begin{abstract}
"E sperávamos contar com mais alunos. E ste projeto deveria ser curricular, mas desenvolvido com ajuda de estagiários que contam com a supervisão permanente de uma professora da universidade, inclusive como foi a nossa com grupos de estudo para discutirmos as questões mais polêmicas, as ex periências na escola e 0 processo. Percebemos que as alunas sentem vergonha em relação aos colegas e quando a orientação é feita por estagiário e não por estagiária... A rotatividade dos alunos dificultou o nosso trabalho em vários sentidos, provocando uma certa desorganização na metodologia de trabalho e ainda corremos o risco de alguns alunos ficarem com conceitos incompletos, errados ou distorcidos... Sugerimos que, nesta escola, o tema Sex ualidade pode ser integrado com 0 tema É tica e Prevenção, portanto pode ser desenvolvido nas disciplinas E ducação Religiosa, Ciências e E ducação Física, como projeto curricular. É neste contex to que os estagiários deverão ser inseridos e não na forma como fizemos..."
\end{abstract}

Este texto chama atenção pelas considerações dos licenciandos, que conseguiram enxergar além de sua própria experiência, considerada positiva e interessante, ao vislumbrarem as necessidades da escola e dos alunos. Um novo saber parece ter sido desenvolvido pelos estagiários, a partir desse exemplo importante de colaboração entre escola e universidade. A escola, como campo de formação inicial e, portanto, de atuação concreta e efetiva na prática docente, forneceu a eles uma diversidade de material a ser discutido na universidade com os colegas e com a supervisora (pesquisadora). Isso permitia, em curto prazo, o retorno dos licenciandos à própria escola com uma atuação mais flexível e educativa. Por sua vez, as discussões nos grupos de estudo contribuíam para maior adesão de outros licenciandos em relação aos problemas reais presentes no cotidianos de sala de aula e escola sobre sexualidade e saúde.

Este projeto possibilitou a visualização de vários problemas: a resistência dos alunos em relação ao debate com os professores sobre assuntos interessantes para todos; a escassa participação dos pais; a tendência dos professores a fugirem do problema, atribuindo a outros a responsabilidade de enfrentá-lo. Parece-nos que, na ocasião, perdeu-se uma possibilidade de troca e integração entre os saberes dos professores, licenciandos, da assessora e psicóloga 
educacional mediante a discussão desses problemas. Em particular, a experiência dos estagiários e as dificuldades dos professores para abordarem durante as aulas cotidianas o tema Sexualidade poderiam ter sido oportunidade para estabelecer uma nova relação entre eles e romper a desconfiança mútua. Provavelmente, a assessora era a única que poderia promover e mediar esse encontro, porém não percebeu essa possibilidade.

\title{
$O$ projeto Vida em Sociedade
}

Seu planejamento foi elaborado durante 0 ano de 2000 e desenvolvido no primeiro semestre de 2001. 0 início foi difícil, pois implicava vários desafios:

- modificar as convicções e os desejos dos professores e da administração pedagógica;

- oferecer mais subsídios metodológicos sobre ensino por projetos aos professores, para superar as dificuldades em implementar ações educativas coletivas integradas na escola e capazes de introduzir inovações na prática dos professores;

- discutir os pressupostos básicos do projeto, as necessidades e possibilidades efetivas de sua implementação.

Além disso, uma longa greve dos professores e a pressão das autoridades educacionais para introduzir as reformas curriculares (a distribuição do Ensino Fundamental em três ciclos, a avaliação por conceitos e a progressão continuada), pareciam não deixar espaço para elaborar e discutir o projeto, que deveria incorporar material de apoio pedagógico encaminhado para a escola pela SEE-MG e pela Superintendência Regional de Ensino-SRE.

Freqüentemente surgiam questões como:

\begin{abstract}
"Por onde comecar? Q ual o lado prático disso? Será que os alunos têm paciência para ouvir o colega falar? Isso é muito bonito, teoricamente funciona, mas para uma sala de vinte alunos e não para quarenta".
\end{abstract}

"D á pra se trabalhar com projetos em todas turmas? A gente vai desenvolver o projeto com os alunos ou eles vão fazer sozinhos? $0 \mathrm{~s}$ alunos vão trabalhar em grupo ou individualmente?"

D e fato, durante todo o ano de 2000 a pesquisadora conseguiu explorar bastante sua influência a partir da posição de outro da escola, na qual foi colocada implicitamente pelos professores, licenciandos e, em parte, pela diretoria. D e alguma forma ela sustentou a elaboração do projeto, não deixando que a iniciativa fosse abandonada, apostando no desejo dos professores de participar de uma inovação escolar e aderir ao onvite das autoridades educacionais. 0 clima de cooperação entre os professores melhorou, principalmente quando a pesquisadora começou a realizar as entrevistas para obter a história de vida das colegas, professoras da escola. Elas comentaram que a reflexão permitia fazer um balanço de suas próprias vidas profissionais e separar o que parecia mera rotina daquilo que, efetivamente, era satisfatório para elas, também percebendo a necessidade que os alunos tinham de ajuda para se envolver nas atividades de ensino em sala de aula.

Para estimular ainda mais a colaboração entre todos, a pesquisadora introduziu uma reflexão sobre as histórias de vida das colegas. Em geral, os comentários dos professores da escola elogiavam as iniciativas novas e até ousadas que eram citadas, sentindo-se encorajados a aplicá-las em suas salas de aula. Porém, o efeito mais profundo da reflexão sobre a vida profis- 
sional das colegas foi a aproximação e, de alguma forma, aumento do desejo de colaborar, sobretudo com algumas delas. Uma professora afirmou que após a entrevista (sobre a história de vida) sua relação com os alunos se modificou, ela se tornou mais atenta aos movimentos deles e começou a aproveitar as idéias do projeto.

"A gente vai descobrindo... é agora que estou aprendendo. Para mim tudo é novo... E stou me sentindo perdida, insegura, demorei para entrar no projeto. E u não conseguia entender. E stava acostumada a entrar e falar, dar aula é mais fácil. Com o projeto é a vez do aluno falar. E u acho que é assim: põe o péna água, daí vooê vai. D aí não é tão difícil assim. 0 rio, ao mesmo tempo que convida, amedronta".

Recortes das quatro histórias de vida e de outras falas de professores na hora do recreio foram trabalhados também em sala de aula, na universidade, sob a forma de Estudos de Casos Pedagógicos (ECP). A análise focalizou como os professores lidavam com suas limitações e como a experiência (prática) contribuía para a construção subjetiva dos saberes docentes. Alguns comentáros de licenciandos:

Lic. 1: "A ssim como o professor... analisado, eu continuo tendo dificuldades na mudança da nota para 0 conceito. Talvez para facilitar eu usasse apenas os conceitos: certo ou errado, ficaria mais fácil. Q ualquer classificação, por nota ou conceito, só permite uma referência da evolução dos alunos... A chei divertido fazer este estudo em classe e em casa. Fui oolocando tudo o que vinha na minha cabeça. A mão trabalhou, insistentemente, para acompanhar as idéias. Não sei se está correto. Tentei mostrar o meu modo de pensar".

Lic. 2: "Talvez refletir seja isto que eu estou fazendo. V oce senta, lêou pensa em alguma coisa que tenha praticado e coloca possíveis oppões... Chega a uma condlusão. Mas, e aí? Q uem disse que aquela opção que escolheu é a œrta? Q uem determina isso? E ntão o œrto e 0 errado são relativos. $\mathrm{V}$ ai de pessoa para pessoa... $\mathrm{N}$ em todos os erros e acertos são relativos. E x istem aqueles que são verdades indiscutiveis".

Os depoimentos das professoras e dos licenciandos chamaram a atenção pelo questionamento efetivo que introduziram na maneira de interpretar a prática didática e constituíram exemplos interessantes de utilização da teoria para aprofundar a análise e atingir o saber pessoal do sujeito.

Finalmente, a estrutura do projeto $\mathrm{V}$ ida em Sociedade foi montada, no final do ano de 2000. 0 tema gerador (Vida em Sociedade) possibilitou, simultaneamente, aprofundar subtemas como: Corpo e gênero nas inter-relações sociais; Educação para o consumo (de energia, de alimentos, de água, de drogas), Brasil atual e futuro... Essa estrutura permitiu a contribuição da maioria das disciplinas. Os professores, em geral, aceitaram o desafio de ensinar articulando simultaneamente os trabalhos em conjunto, que ocupavam uma das aulas semanais, aos trabalhos tradicionais referentes aos conteúdos mais específicos do programa das disciplinas. Sugestões eram dadas por professores a outros colegas que tinham dúvidas: 
P1: "Podemos orientar os alunos para criação de mural, usar jornais... e inœentivar a pesquisa. Promover debates para provocar polêmicas e estimular a leitura, argumentação, construção de frases, paródias e música. N ão é assim?"

\section{P2: "C omo trabalhar E ducacãa para o C onsumo em Matemática?"}

P3: "C onsumo, na idéia de equilíbrio e perigo, não poderia ser trabalhado com a estatística aplicada à Prevenção?"

Alguns professores superaram, gradualmente, a resistência a pensar coletivamente as dificuldades de compreensão em relação ao objetivo do projeto e ao significado da abordagem metodológica; aos poucos, levantaram a necessidade de organizar as atividades da escola e começaram a pensar no compromisso de todos.

A contribuição definitiva para a implantação do projeto veio a partir da decisão da SRE de que, no ano seguinte, 2001, o planejamento escolar deveria ser feito por série ou ciclo, na forma de projeto, e não mais por disciplina. Diretoria, professores e funcionários estavam satisfeitos por terem-se antecipado em relação às demandas sobre inovações curriculares da SRE, que, por sua vez, considerava a escola exemplo a ser seguido pelas outras. Para o professorado, uma ilusão grupal, "somos uma esola ex emplar", operava um efeito aglutinador, recalcando as divergências individuais e promovendo um querer comum. A própria diretora foi capturada nesse movimento e manifestava abertamente seu apoio.

Com o início das atividades do projeto, apareceram sucessos e dificuldades. 0 comentário de uma professora mostra sua satisfação:

"E stou trabalhando com regiões assim, talvez seja bom pra vooês também. E les (os alunos) já comecaram a procurar material em casa, depois vamos fazer painéis om gravuras e estudos, diferenças culturais... em sala de aula mesmo. E les gostam de montar painés. A gora começamos a discutir sobre sotaque nas regiōes, eles adoram... junto com isso vou pedir pra eles montarem um teatrinho pequeno, usando o sotaque de cada região, por grupo..."

No entanto, para alguns professores as dificuldades ainda continuavam bloqueando a entrada para o caminho da mudança: apesar de estarem muito perturbados com o movimento dos colegas, ainda não se sentiam mobilizados para intervir na própria prática e, conseqüentemente, no macro da realidade escolar:

"E stamos todos perdidos... Q ue dia mesmo eu posso começar?... 0 que vou levar para os alunos faz erem?"

Em síntese, o projeto Vida em Sociedade, lentamente, foi sendo executado como um processo legítimo de modificação curricular, com contribuições da escola e da universidade. Parece que a natureza e o conteúdo dos temas que constituíram a matriz do projeto tornaramse uma ponte adecuada para auxiliar os professores a abandonar o medo de um ensino com estratégias diferentes da simples rotina disciplinar. D e um lado, as reuniões pedagógicas sobre o projeto eram sistemáticas, mas envolviam um tempo limitado. A proposta não constituía 
abandono da tradição e dos conteúdos disciplinares. As eventuais perdas em ministrar o conteúdo disciplinar específico eram compensadas pelo ganho em discutir conteúdos mais ligado à vida cotidiana e favorecimento de atitudes e valores ligados ao exercício da cidadania. Por outro lado, os professores, ao longo do projeto, começaram a perceber que a dicotomia projeto/ disciplina não correspondia à realidade e que, de fato, os alunos, em geral, tinham uma aprendizagem muito limitada durante 0 tratamento exclusivamente disciplinar. 0 projeto estava ajudando os alunos a aprenderem melhor os conteúdos disciplinares, pois o envolvimento e a satisfação de todos, alunos e professores, era maior que anteriormente. Um ponto importante a ser salientado é que a estrutura do projeto, ou seja, o equilíbrio entre o tradicional e a inovação, parece ter permitido colocar em jogo a modificação lenta do saber docente dos professores.

Assim, aos poucos, o projeto foi reconhecido e sustentado internamente na instituição escolar, porque conseguia atingir o desejo implícito da maioria dos professores de aderir às reformas educacionais sem abandonar suas competências e seus saberes. Em razão disso, tornou-se uma reforma de acordo com as possibilidades dos professores. 0 projeto era reconhecido pela SRE como inovador, enquanto os professores estavam sentindo-se à frente da demanda externa e reivindicando espaço para lideranças locais. Essa mudança foi altamente significativa, pois no início da experiência a SRE exercia apenas um papel perturbador da prática dos professores, ao passo que, quando as perspectivas dos professores se acoplaram à demanda da secretaria, o efeito foi muito reforçador e contribuiu fortemente para a criação de um clima final positivo.

Na universidade, a introdução dos futuros professores no universo da prática a partir da reflexão sobre os depoimentos dos professores ajudou a pesquisadora a desenvolver uma formação inicial mais interessante e realista, além de preparar os licenciandos a enfrentar de maneira mais competente os desafios nos futuros estágios docentes curriculares. $\mathrm{O}$ contato inicial dos estagiários com a realidade da escola, via discussão, na universidade, das idéias dos docentes, permitiu o confronto com seus próprios conhecimentos e saberes já construídos e, também, um início de reflexão sobre os saberes profissionais docentes. Enfim, os comentários de professores e licenciandos sobre as falas ou os depoimentos de colegas permitem inferir que essa atividade favorecia a elaboração de um novo "saber docente reflexivo" sobre e na prática, ou seja: a modificação e utilização de um saber anterior a partir da identificação e apropriação de sugestões de outros e das contribuições da pesquisadora. 0 clima de parceria permitia que cada um pudesse questionar, ao menos em parte, sua próprias crenças pedagógicas. Uma via de mão dupla entre universidade e escola tinha começado a funcionar: a reunião e colaboração da pesquisadora com os professores e licenciandos numa atividade comum bastante estável, planejando atividades em favor da comunidade escolar (autoridades, colaboradores, professores, alunos, funcionários e pais).

\section{$O$ projeto Viajando pelos Continentes}

D urante o segundo semestre de 2001, a pesquisadora precisou reduzir sua atuação como assessora, por causa de compromissos acadêmicos. D e certa forma, essa circunstância representou um teste para o início da emancipação dos professores, os quais criaram e desenvolveram um novo projeto: $\mathrm{V}$ iajando pelos $\mathrm{C}$ ontinentes. Segundo os professores, foi um desdobramento do projeto anterior, porque nele também foram explorados os valores, costumes e 
crenças das sociedades. D oze países de três Continentes (América, Europa e Ásia) foram investigados em relação à cultura, política, economia e geografia, procurando desenvolver a perspectiva dos alunos em favor da cidadania e da paz mundial. Q uase todos os professores se mobilizaram, de maneiras diferentes, em favor deste projeto, que constituiu sinal da potencialidade do grupo de docentes organizado a partir da liderança da vice-diretora (ex-professora do ciclo básico do Ensino Fundamental) e da pedagoga educacional da escola. Nele, sobretudo no início, o maior combustível para o avanço esteve vinculado aos primeiros resultados que apareciam quando as atividades ganhavam existência coletiva na escola durante as aulas, propiciando, inclusive, novas adesões de professores e mais apropriação da idéia. Um outro elemento que colaborava com a adesão dos professores e 0 envolvimento dos alunos era a ressonância de suas percepções sobre o projeto como uma modalidade diferente e eficaz no Ensino Fundamental. De um lado, os alunos percebiam que, trabalhando na forma de projeto, eram mais respeitados e valorizados pelos professores e, por isso, desenvolviam melhor suas potencialidades. Os professores, por sua vez, observavam uma progressiva mudança no comportamento dos alunos, quando estes se sentiam navegando por outros espaços e aprendendo com maior entusiasmo. De fato, todos os professores, com exceção de dois, atuaram como coordenadores de classe, independente de sua área específica, acompanhando uma classe desde 0 pré-planejamento, passando pela preparação e apresentação, até a discussão do relatório em classe, concluindo com a avaliação individual, do grupo e do projeto. Esta última atividade constituiu a conclusão do estudo da classe: em primeiro lugar era avaliado o que foi aprendido em relação aos países pesquisados nos aspectos culturais, econômicos, políticos e geográficos; em seguida, a avaliação analisava o sentido da formação integral, mais especificamente, as atitudes dos alunos, dos professores e demais pessoas da escola; finalmente, era discutida a relevância do projeto para a comunidade escolar e eram levantadas possíveis críticas e sugestões em relação às condições encontradas nos países visitados.

Em resumo, durante todo o projeto o clima foi de inovação e confiança, pois, segundo os relatos de vários professores e alunos, tal experiência foi se desenvolvendo com sucesso desde o planejamento até a avaliação. Em particular em setembro de 2001, quando nos Estados Unidos aconteceu 0 atentado contra 0 W orld Trade C enter, houve um momento no qual 0 projeto tornou-se altamente mobilizador. Todos perceberam que 0 estudo que estavam desenvolvendo não somente tinha relações com os eventos que dominavam a opinião pública mundial, mas, também, que ensinar e aprender, segundo a modalidade didática de projetos, permitia maior participação e interpretação desses eventos de forma muito mais ampla e aprofundada que na forma tradicional das aulas expositivas. Para professores e alunos, ensinar e aprender pela pesquisa em grupo era, efetivamente, um dispositivo de emancipação cultural e de exercício da cidadania.

Alguns pontos merecem destaque: 0 projeto $\mathrm{V}$ iajando pelos Continentes representou uma continuidade e um avanço em relação ao passado, constituindo uma re-edição do entusiasmo e das perspectivas da Feira Científico-Cultural num nível mais integrado. De fato, o desenvolvimento desse projeto tinha raízes que começaram a ser desenvolvidas quando, na avaliação da Feira, percebeu-se, de um lado, a receptividade dos professores e dos alunos em relação ao trabalho coletivo e, por outro lado, a potencialidade e o interesse do tema aprofundado. Finalmente, o projeto foi desenvolvido e concluído com suporte limitado da pesquisadora, sinalizando certo amadurecimento dos professores e colaboradores mediante a apropri- 
ação de novos saberes pedagógicos, relacionados ao trabalho em conjunto. A presença limitada da pesquisadora e o surgimento de lideranças locais tiveram como efeito um esvanecimento da dependência dos professores em relação à assessora e um deslocamento de sua influência; ela se tornou uma colaboradora com olhar externo ao projeto institucional escolar. As lideranças estavam experimentando uma satisfação nova: sustentar um projeto até sua conclusão, experimentando o vínculo de um esforço em comum e abandonando a satisfação mórbida de assistir ao fracasso de todas as iniciativas.

Infelizmente, a redução da disponibilidade de tempo da pesquisadora em relação à experiência nessa escola implicou também a suspensão da participação dos licenciandos nas correspondentes atividades e na reflexão sobre elas. Houve um deslocamento dos licenciandos para outras escolas, sinalizando que a estrutura de colaboração entre universidade e escola era ainda extremamente precária e dependente de iniciativas individuais de seus docentes.

\section{Algumas considerações finais}

Neste trabalho relatamos e analisamos uma experiência simultânea, mesmo que provisória, de formação inicial e continuada de professores e licenciandos, ao longo de três anos, que teve como elemento catalisador a participação de estagiários, de professores e de uma assessora pedagógica voluntária, no dia a dia de uma escola pública de Ensino Fundamental marcada pela implantação das reformas curriculares na Educação Básica. Os licenciandos experimentaram diagnóstico, investigação, planejamento, ensino e avaliação no processo educativo da escola, fazendo interlocução permanente com o conhecimento acadêmico; os professores tiveram a oportunidade de participar como sujeitos de uma formação continuada na ação, ou seja, na própria escola, enquanto modificavam a realidade educativa escolar; a assessora (professora de Prática de Ensino de Biologia na universidade) melhorou simultaneamente seu ensino e sua pesquisa a partir de suas intervenções na escola e dos respectivos resultados. Essa experiência constituiu ocasião importante para refletir e problematizar os obstáculos, as dificuldades, necessidades e possibilidades da prática docente envolvida com reformas curriculares, além de provocar mudança nos conhecimentos e saberes docentes de todos os participantes das experiências analisadas.

Pensamos que, no caso dos professores, essa mudança aconteceu graças ao acoplamento de dois elementos fundamentais. D e um lado, o aprimoramento nas relações interpessoais e a superação, mesmo que inicial, de conflitos, dúvidas e inseguranças abriram o caminho para a saída dos professores de uma situação de inércia, dominada por suas queixas-lamento, para a introdução de ações coletivas e colaborativas. D e outro, sua participação em vários projetos pedagógicos institucionais sustentou a busca de solução para o conjunto de problemas relacionados ao ensino propriamente dito. Essa participação promoveu mudanças específicas na prática docente, pois tornou os professores mais preocupados com o planejamento, a aprendizagem e a avaliação; enfim, colocou a escola em sintonia com a conquista de uma autonomia que, sem dúvida, exigia aprendizados individuais e coletivos da comunidade escolar. 0 ensino pelo método de projeto serviu, também, para mobilizar toda a comunidade escolar, que passou a experimentar a satisfação de dar mais sentido social aos trabalhos, de 
tomar decisões em conjunto e realizar ações coordenadas. Isso permitiu que os projetos se tornassem, progressivamente, mais originais e autônomos, inclusive porque a escola pôde contar com 0 apoio das reformas educacionais e o reconhecimento da comunidade mais ampla (BARCELOS, 2001). Parece-nos que o ponto fundamental da mudança curricular foi tornar o processo auto-sustentado, ou seja, com seus atores adquirindo progressiva motivação e capacitação para perceber possibilidades, onde, anteriormente, somente enxergavam dificuldades.

No caso da assessora, a experiência teve vários efeitos. Em primeiro lugar, serviu para aprimorar sua capacidade de escuta dos problemas da escola e, conseqüentemente, flexibilizar suas intervenções e, enfim, modificar seus saberes docentes como formadora de professores. Seu projeto de pesquisa inicial sofreu profundas modificações ao longo dos três anos de participação na vida da escola. Além disso, os projetos de ensino desenvolvidos constituíram fonte de dados e campo de experimentação para sua prática didática na universidade, enquanto formadora de futuros professores. Não somente eventos do dia a dia escolar tornaram-se objeto de reflexão na universidade, mas também foi possível uma participação, mesmo que eventual e inicial, dos licenciandos em alguns dos projetos educativos da escola. A assessora entrou na escola com um projeto inicial de pesquisa, mas ao perceber as possibilidades algumas vezes surpreendentes - que apareceram, deixou-se conduzir pelas mesmas, modificando seus saberes como formadora, privilegiando a implementação de projetos de ensino e pesquisando o correspondente processo. Os resultados a deixaram convencida de que aquela escola podia ser considerada, a partir daquele ano, um campo formativo promissor para seus licenciandos, principalmente em relação ao ensino por projetos.

Entretanto, no início de 2002, dois professores e uma pedagoga que tinham colaborado intensamente com o desenvolvimento dos projetos anteriores deixaram a escola, que perdeu boa parte do impulso para as inovações. D e fato, naquele ano, os estagiários da modalidade Conheca uma E soola, visitaram a escola procurando verificar a continuidade do ensino por projetos e, infelizmente, encontraram poucos vestígios do clima anterior de inovação. É interessante notar que se o afastamento da assessora, em 2001, teve papel mobilizador na escola, promovendo lideranças que conseguiram ocupar, em boa parte, o espaço deixado por ela, o afastamento das novas lideranças parece ter deixado um vazio muito maior, que desestruturou 0 grupo.

Finalmente, no caso dos licenciandos, vários efeitos foram observados. Os que participaram das reflexões na universidade, via ECP, puderam questionar suas crenças e ampliar suas capacidades de análise da realidade escolar. Os que participaram dos projetos escolares tiveram contato com as dificuldades básicas da escola e experimentaram algumas possibilidades de solução. O s que participaram da observação sistemática da escola ficaram efetivamente perturbados com esse contato: um resultado altamente promissor dessa introdução à realidade escolar foi a vontade dos licenciandos de discutir, a partir do suporte teórico estudado na universidade, os problemas, as dificuldades e soluções percebidas. Enfim, uma série de experiências pedagógicas, mobilizadoras quanto à mudança de saberes e valorização da profissão docente.

\section{Aprofundando a interpretação}

Várias questões podem ser levantadas, a partir dessa síntese, para aprofundar as características da experiência: 
Q ual o papel da assessora no desenvolvimento de situagões tão complex as? Parece claro que ela percebeu implicitamente a existência de um espaço vazio na escola, que permitia a repetição de vários círculos viciosos. Ao ocupar este espaço, abriu a possibilidade para que um novo saber, capaz de perturbar as práticas repetidas e introduzir novas práticas, fosse gerado, ao menos inicialmente. A resistência e impotência, que marcavam as queixas-lamento dos professores, amarrando-os em circuitos de gozo que se repetiam sistematicamente, com sua ajuda começaram a ser transformados em desafios, conflitos e novas idéias. Freqüentar a sala de professores foi, para a assessora, uma maneira de estar presente num cenário dinâmico da prática com suas múltiplas oportunidades que lhe permitiu, além de ouvir, observar, criticar mentalmente e anotar, também viver o clima emocional e contextual da escola. Os professores, aos poucos, começaram a pedir teorias para interpretar e enfrentar os desafios da prática. Hipotetizando: 0 papel inicial da assessora, ao manter vivo seu próprio desejo de promover mudança na escola, conseguiu favorecer o aparecimento do desejo dos professores. Os professores percebiam que ela queria algo, investindo para alcançá-lo e esse querer era fonte de segurança para eles, porque contrastava com a ambigüidade dominante na escola. Provavelmente, essa presença tenha se tornado ainda mais eficiente quando ela resolveu apostar no projeto integrado $\mathrm{V}$ ida em Sociedade. Isso implicou sustentar esse querer durante todo o segundo ano de assessoria. Aos poucos, o que ela queria estava se tornando realidade. 0 outro papel fundamental da pesquisadora foi perceber as potencialidades da experiência na escola para a formação de professores na universidade. Essa percepção foi gradual. No começo, limitou-se a explorar a ajuda de alunos e ex-alunos em alguns projetos eventuais da escola; em seguida, inverteu a direção da ajuda, aproveitando dados recolhidos em sua pesquisa, principalmente pelas histórias de vida de algumas professoras, para estimular a reflexão de seus licenciandos. A experiência abriu a possibilidade de resultados altamente promissores, como a introdução à realidade escolar dos licenciandos e o início de uma colaboração mais estreita entre os professores da escola, a assessora e os licenciandos.

Q ual o papel dos professores no processo? Sem dúvida, houve um papel inicial fundamental: sinalizar seu desejo de mudança. As várias iniciativas que surgiam na escola e eram progressivamente abandonadas tinham um duplo significado: desejo efetivo e falta de liderança. Q uando a assessora preencheu essa falta, convocando implicita e explicitamente os professores a participarem das reformas curriculares, houve uma resposta efetiva dos professores. No começo alguns aceitaram o convite, depois outros e, finalmente, a maioria. No começo a resposta era participar de projetos limitados, depois participar de projetos integrados, depois elaborar projetos autônomos. Sem essa resposta, provavelmente, nada teria mudado efetivamente; sobretudo, a escola não teria conseguido a autonomia parcial que experimentou ao final da experiência. Em resumo, parece-nos que o papel fundamental foi responder aos convites da assessora com pequenas mudanças efetivas, que abriam espaço para ulteriores mudanças. 0 fato da saída definitiva da assessora e de algumas lideranças locais ter tido como efeito a quebra do processo de renovação sugere que o coletivo da escola ainda não tinha atingido uma situação grupal de amadurecimento, no qual a liderança pudesse ser exercida de forma rotativa, dependendo da necessidade.

Q ual o papel da diretoria? Aceitou a entrada da assessora, permitindo sua atuação inicialmente limitada e, depois, sempre maior. Também deixou que surgissem iniciativas dos professores e fossem iniciadas as mudanças propostas pela SRE, mas não as sustentava, no sentido de 
coordenar e fornecer os recursos necessários para sua realização. Ao entrar na escola, a pesquisadora percebeu esta lacuna, mas não investiu muito na tentativa de provocar uma mudança da diretora de sua posição inicial. Nossa hipótese é que a estabilização do processo de atualização necessita de mais que um motor temporário sustentado por lideranças externas ou até internas; precisa da 'conspiração' entre essas lideranças e a aprovação institucional, sendo esta última 0 intermediário das sucessões nas lideranças. Essa conspiração realizou-se no terceiro ano da experiência, na ocasião da aprovação, por parte de SRE, das iniciativas da escola, que estimulou a diretoria a apoiar efetivamente - e não somente permitir - os projetos propostos. Esse apoio facilitou a passagem da liderança estreita da assessora para as lideranças locais, que puderam sustentar com bastante autonomia o projeto $\mathrm{V}$ iajando pelos Continentes. Q uanto ao retrocesso encontrado no final de 2002, podemos supor, pelo histórico da experiência, que a diretoria não conseguiu intermediar o preenchimento do vazio a partir da saída de alguns dos atores mais ativos do coletivo. A posteriori, podemos nos perguntar se um maior investimento da assessora na mediação entre os professores e a diretoria não teria favorecido, por parte desta, assumir de maneira mais efetiva e sistemática a sustentação das iniciativas e dos projetos da escola.

Q ual o papel dos licenciandos-estagiários? Eles participaram dos projetos, puderam aproveitar a experiência para entrar em contato com a realidade de uma escola em transformação e trocaram com seus colegas esse saber inicial adquirido na prática. Tiveram, também, o papel de sinalizar aos professores a possibilidade de uma colaboração profícua com a universidade, complementando a ação da assessora. Era a primeira realização incipiente de uma colaboração de 'mão dupla'. O s licenciandos-estagiários que observaram a vida da escola, ao discutirem os problemas escolares não somente modificavam seu próprio saber, mas auxiliavam sua professora a focalizar os pontos-chave das dificuldades gerais que a escola estava passando a partir das mudanças curriculares exigidas pela SRE. Entretanto, é preciso salientar que eles não chegaram a ter uma responsabilidade efetiva sobre o desenvolvimento das mudanças curriculares.

Q ual o papel da esola como campo de formação inicial e continuada? Parece que a intervenção na escola favoreceu uma modificação da realidade dos professores, ou seja, seu saber e seu ambiente. Essa intervenção partiu da consideração das reais condições de trabalho, escuta dos discursos da comunidade escolar, interpretação dos comentários do professorado sobre suas próprias práticas, bem sucedidas ou não; ela estava disponível, também, para mediar os efeitos dos discursos externos oficiais. Além disso, essa intervenção conseguiu se acoplar a um projeto mais amplo, que incluiu a formação inicial dos licenciandos na universidade, graças aos resultados das colaborações iniciais, eventuais, e quase casuais, de alguns deles nos projetos da escola.

\section{Novos horizontes}

Com este trabalho tentamos mostrar que é possível e, talvez, necessário estabelecer uma 'via de mão dupla' entre universidade e escola. A nosso ver, é importante que os professores da Educação Básica, ao serem convidados pelos formadores de professores da universidade a inovar sua prática, compreendam que isso significa pensar juntos sobre o que fazer e como fazê-lo. Por outro lado, mais importante ainda é que os formadores de professores, enquanto colaboram com esta tarefa, melhorem sua compreensão acerca da dinâmica e dos limites da realidade escolar e encontrem subsídios e espaços significativos para modificar a formação inicial pela qual são responsáveis. 
Entendemos que a fragilidade nas relações institucionais entre universidade e escola tem contribuído para a manutenção do distanciamento entre saber acadêmico e saber profissional docente, apesar da existência de inúmeros programas institucionais, na maioria das vezes isolados e sem uma articulação institucional. Esses programas ainda privilegiam uma formação continuada na qual os professores não conseguem se encontrar como sujeitos em mudança, não existe espaço para as discussões coletivas dos projetos e sua aplicação em sala de aula não é apoiada sistematicamente. Por outro lado, parece essencial e necessária a utilização da escola como lugar da formação inicial para a construção de saberes por parte dos futuros professores, porque ela oferece situações reais contextualizadas. Compartilhamos do pressuposto de que ser professor/ a implica construção de um repertório de saberes docentes, a partir de ações educativas refletidas com ajuda teórica, porém no contexto das relações sociais que caracterizam a organização escolar. Portanto, torna-se premente 0 reconhecimento da escola como espaço necessário para o desenvolvimento de uma cultura profissional baseada no intercâmbio de experiências e na reflexão compartilhada entre universidade e escola, porque os saberes profissionais, que englobam conhecimentos, competências, habilidades e atitudes são mobilizados, construídos e incorporados somente na prática (TARDIF, 2000). Eles implicam, também, investimento que os torne conquistas subjetivas.

Na pesquisa analisada houve uma articulação entre a formação continuada e a inicial, mesmo que de forma incipiente.

O ponto importante foi que o conjunto de intervenções psico-pedagógicas e sociais da pesquisadora contribuiu para fazer emergir na escola lideranças locais, que conseguiram mediar e orientar as ações educativas coletivas por um certo tempo. $\mathrm{Ou}$ seja, podemos interpretar que, no momento originário (KAËS, 1997) ${ }^{11}$ que constituiu a fundação do grupo analisado, a pesquisadora e os professores estabeleceram vinculação e identidade entre seus sonhos (ontrato narćsico) e um acordo inconsciente (pacto denegativo) do que devia ser mantido recalcado, constituindo as condições psíquicas e sociais necessárias para o desenvolvimento do agrupamento institucional e para a escolha dos intermediários que conduziram o grupo e seus projetos a uma maior aderência à realidade nas transições e rupturas. Entretanto, isso não se repetiu na ocasião em que as lideranças locais saíram da escola; não houve um novo momento originário com novos pactos para levar adiante as mudanças curriculares e enfrentar os novos desafios. Sem dúvida, é preciso prestar atenção a essas condições quando são propostas mudanças que envolvem articulações entre grupos e colaborações entre instituições.

Em síntese, a 'via de mão dupla' entre universidade e escola, que estamos vislumbrando, poderá produzir benefícios recíprocos. De um lado, os professores da escola poderiam auxiliar na integração dos licenciandos à vida da escola, durante o processo de formação inicial,

\footnotetext{
${ }^{11}$ Para K aës existe um momento oniginánio de constituição do grupo, no qual são construídos tanto uma identificação entre cada um dos membros para a realização de seus desejos (contrato narcísico comum) quanto os mecanismos de defesa contra os perigos que podem ameaçar a grupalidade em construção (pactos denegativos). 0 conceito de intermediário é proposto como mecanismo de passagem, em um momento de ruptura. Esse intermediário, que pode ser inclusive uma idéia, é construído para assegurar os apoios narcísicos necessários para o desenvolvimento tanto do sujeito como do grupo.
} 
acompanhando sua atuação nos estágios, auxiliando-os com seu monitoramento, suas sugestões e seus exemplos de docência. Por sua vez, os professores da universidade, ao coordenarem os estágios adaptando-os à realidade da escola, poderiam ampliar seu saber como formadores de professores e contribuir para a produção de novos conhecimentos no campo educacional. Esse encontro na escola poderá promover simultaneamente a atualização dos docentes, auxiliando-os na reflexão sobre sua prática. Certamente, o problema mais difícil será articular essa triangulação de forma que professores, licenciandos e docentes universitários experimentem um vínculo grupal, gerador de um novo tipo de satisfação e capaz de modificar suas rotinas e estabilizar sua colaboração. Parece-nos que a institucionalização dessa prática, para poder se sustentar durante os impasses, improvisações e "pequenos incêndios" que acontecem em qualquer processo inovador, deverá ser ancorada numa dinâmica grupal com utopias e pactos partilhados pelos participantes, ou seja , num projeto efetivamente comum.

Parece-nos que esta seria uma forma interessante de eqüacionar os fatores que interferem na formação inicial e continuada dos professores do país, de acordo com a declaração de Cochabamba (PRADA et al., 2001, p. 79) na qual se propõe:

um enfoque sistêmico, integrador da formação inicial com a formação continuada, com a participação efetiva dos docentes em projetos de formação, geradores de equipes de trabalho e pesquisa nas escolas, que organizem e executem coletivamente seus próprios projetos políticos-educativos, respondendo às necessidades e diversidade da comunidade que atendem. 


\section{Referências}

BARCELOS, N. N. S. A prática e os saberes docentes na voz de professores do Ensino Fundamental na travessia das reformas educacionais. São Paulo, 2001. Dissertação (Mestrado) - Faculdade de E ducação, USP.

BARBIER, R. A Pesquisa-ação. Tradução Lucie Didio (UNB). D ez. 1997. mimeografado.

BARO LLI, E.; FRANZO NI, M.; VILLANI, A.; FREITAS, D. A crônica da disciplina: uma experiência na formação de professores de ciências. Rev. Bras. Pesqu. Educ. Ciênc., v. 1, n. 3, p. 136-148, 2001.

COLLARES, C. A. L.; MOYSÉS, M. A. A. Construindo o sucesso na escola: uma experiência de formação continuada com professores da rede pública. Caderno CEDES, v. 36, n. 95, p. 111, 1995.

COMPIANI, M. et al. Parceria entre universidade e escola pública para a formação continuada de professores do ensino fundamental com temas de geociências. In: ENCONTRO NACIONAL DE PESQUISA EM EDUCAÇÃO EM CIÊNCIAS, 3., 2001, Atibaia. Atas...Porto Alegre: ABRAPEC, 2001, p. 12. 1 CD-ROM.

FERNÁNDEZ, A. A mulher escondida na professora: uma leitura psicopedagógica do ser mulher, da corporalidade e da aprendizagem. Porto Alegre: Artes Médicas, 1994. 107p.

FINK, B. 0 sujeito lacaniano- entre a linguagem e o gozo. Rio de Janeiro: Jorge Zahar, 1998.

FREITAS, D.; VILLANI, A.; PIERSON, A. H. C.; FRANZINO, M. Conhecimento e saber em experiências de formação de professores. In: ANPED, 23., 2000, Caxambú. Atas..., Caxambú, 2000. 16p. 1 CD-ROM.

GARRID O, E.; PIMENTA, S. G. ; M., M. O. A pesquisa colaborativa na escola como abordagem facilitadora para o desenvolvimento da profissão do professor: In: MARIN, A. J. (org). Formação continuada. Campinas: Papirus, 2000.

KAËS, R. 0 grupo e o sujeito do grupo: elementos para uma teoria psicanalítica do grupo. Tradução José de Souza e Mello Werneck. SãoPaulo: Casa do Psicólogo, 1997.

MINISTÉRIO DA EDUCAÇÃO E DO DESPORTO. Proposta de diretrizes para a formação inicial de professores da Educação Básica, em cursos de nível superior. Maio/ 2001. 
MRECH, L. M. Psicanálise e Educação: novos operadores de leituras. São Paulo: Pioneira, 1999.

PACCA, J. L. A.; VILLANI, A. Un curso de actualización y cambios conceptuales en professores de Fisica. Enseñanza de las Ciencias, v. 14, n. 1, p. 25-33, 1996.

PRADA, L. E. A.; PASSO S, L. F. ; FILHO, P. C. Educação continuada dos profissionais do ensino. In: CONGRESSO ESTADUAL PAULISTA SOBRE FORMAÇÃO DE PROFESSO RE S, 6., 2001. Atas... p. 77-88.

PREFEITURA DE BELO HORIZO NTE. Escola Plural: proposta político-pedagógica. Caderno Temático, n. 4, 1994.

TARDIF, M. Saberes profissionais dos professores e conhecimentos universitários: elementos para uma epistemologia da prática profissional dos professores e suas conseqüências em relação à formação para o magistério. Revista Brasileira de Educação, v. 13, p. 5-24, 2000.

VILLANI, A.; PACCA, J. L. A.; FREITAS, D. Formação do professor de Ciências no Brasil: tarefa impossível? In: ENCONTRO NACIONAL DE PESQUISA EM ENSINO DE FÍSICA - EPEF, 7., 2002. Atas... 2002. p. 21. 1 CD-ROM. 
